\title{
Renal Vascular Anatomic Abnormalities During Open Abdominal Aortic Repair
}

\author{
Domenico Baccellieri, Vincenzo Ardita, \\ Gianbattista Tshiombo, Enrico Rinaldi, \\ Yamume Tshomba, and Roberto Chiesa
}

\subsection{Introduction}

Renal arteries are defined as a pair of lateral branches from the abdominal aorta. Anatomical dissection studies have revealed that in most cases, each kidney receives one renal artery and one renal vein is deputy to drain blood into the inferior vena cava. The left renal vein also

Electronic Supplementary Material The online version of this chapter (doi:10.1007/978-3-319-94761-7_5) contains supplementary material, which is available to authorized users.

D. Baccellieri $(\bowtie)$

Unit of Vascular Surgery, San Raffaele Scientific

Institute, Milan, Italy

e-mail: baccellieri.domenico@hsr.it

V. Ardita $\cdot$ E. Rinaldi

Vascular Surgery Unit, IRCCS San Raffaele Scientific Institute, Milan, Italy

G. Tshiombo

Vascular Surgeon, Fondazione Cariplo, Milan, Italy

Y. Tshomba

Unit of Vascular Surgery, Fondazione Policlinico

Universitario A. Gemelli IRCCS, Università Cattolica del Sacro Cuore, Rome, Italy

Unit of Vascular Surgery, San Raffaele Scientific

Institute, Vita-Salute University,

Milan, Italy

R. Chiesa

Unit of Vascular Surgery, San Raffaele Scientific

Institute, Vita-Salute University,

Milan, Italy receives left suprarenal and left gonadal veins, in addition to the vein coming out from the kidney.

Variations in number, source, and course of the renal arteries are common, occurring in $60-80 \%$ of reported cases $[1,2]$. The renal artery may give rise to branches normally derived from other vessels, such as the inferior phrenic, hepatic, suprarenal, gonadal, pancreatic, and lumbar arteries.

The abnormalities in the renal arteries are mainly due to the various developmental positions of the kidney, and the different origin and their variations are explained by the development of mesonephric arteries.

During the development in the pelvis, both kidneys are supplied by common iliac artery branches, but later, during migration into the lumbar region, their arterial supply shifts to the abdominal aorta.

Extrarenal artery may be classified into:

- Aberrant renal artery

- Accessory renal artery

Aberrant renal arteries commonly supply the superior or inferior pole of the kidney.

Accessory renal arteries are a common variant and are present in $\sim 25 \%$ (range $20-30 \%$ ) of the population. They may originate from the abdominal aorta, either above or below the main renal artery or, on rare occasions, from iliac arteries. 
Accessory renal arteries occur bilaterally in $10-15 \%$ of cases:

- Single renal artery arising from the abdominal aorta: $70 \%$

- Double renal arteries 20\% (range 14-23\%)

- Triple renal arteries $2.5 \%$ (range 1-4\%)

- Quadruple renal arteries $<1 \%$

Proper identification is mandatory for surgical planning prior to live donor transplantation, renal artery procedures, and aortic surgery. Techniques proposed for reducing the incidence of renal failure in the presence of aberrant renal arteries and concomitant abdominal aortic aneurysm (AAA) are the aortic patch, singlevessel reattachments through bypass grafts, or direct reattachment (Figs. 5.1 and 5.2 and Movie 5.1).
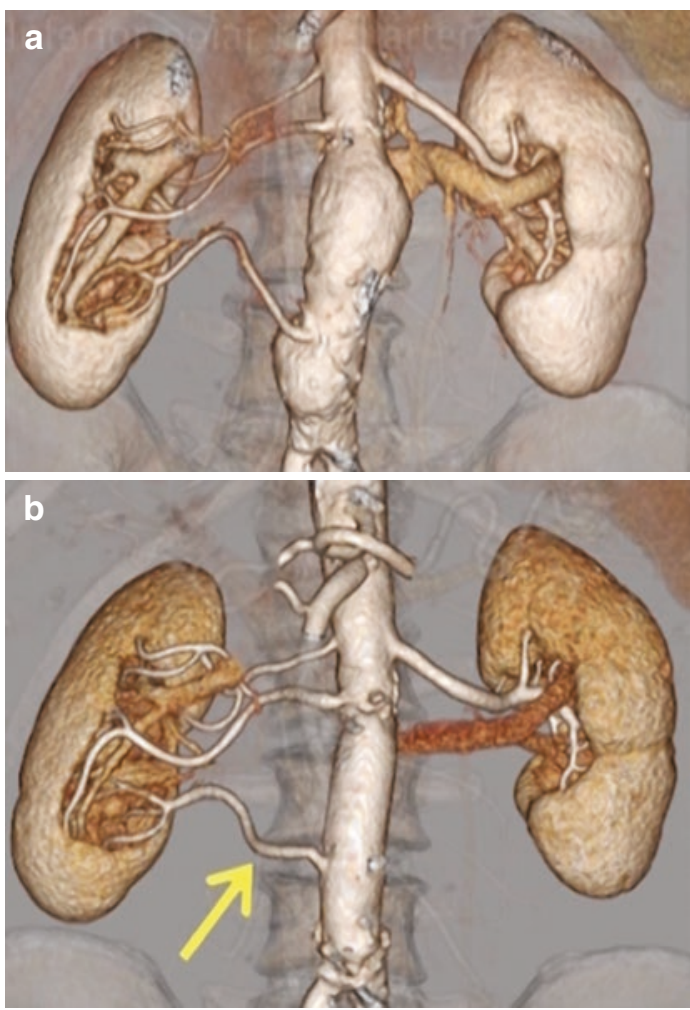

Fig. 5.1 AngioCT showing an infrarenal abdominal aortic aneurysm with an inferior right polar artery requiring reattachment during tube graft repair (a) and postoperative angioCT showing the same case after aortic repair and inferior right polar artery reattachment (b). The pictures in
During aberrant artery reattachment, cold crystalloid perfusion can be used in order to reduce the risk of tubular damage (Movie 5.1).

Renal anomalies are described in the literature and can all be stratified into two categories: the horseshoe kidney and the pelvic kidney.

\subsection{Horseshoe Kidney (HSK)}

Horseshoe kidney (HSK) is a well-known congenital fusion across the midline of two distinct functioning kidneys found in $0.25 \%$ of the general population and is characterized by the medial fusion of the two kidneys anteriorly, or occasionally posteriorly, to the aorta [3-6].

Incidence is between 1:600 and 1:800 and is twice as common in men.

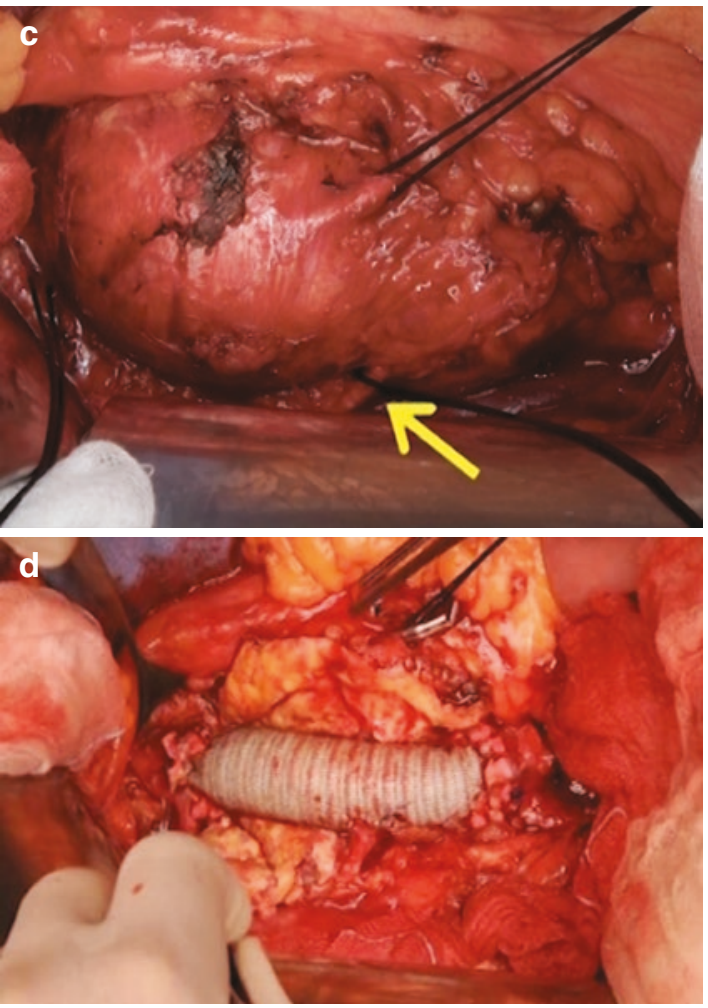

the operating room show the same case before (c) and after repair (d). Of note, in (c), the arrow indicating inferior right polar renal polar artery and the vessel loop around the inferior mesenteric artery 


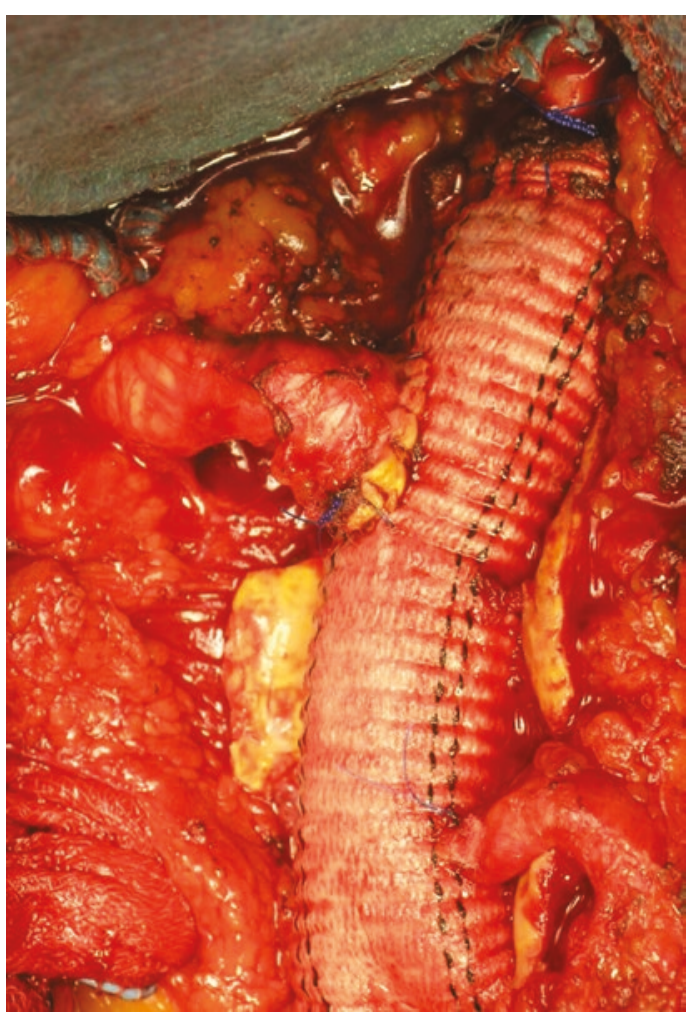

Fig. 5.2 Intraoperative imaging showing direct reattachment of the right renal artery during an AAA tube graft repair with concomitant right aberrant renal artery. Of note, on the right side, the reimplantation of the inferior mesenteric artery as well

The kidneys are connected by an isthmus of either functioning renal parenchyma or fibrous tissue [7]. In the vast majority of cases, the fusion is between the lower poles (90\%). The remainder of the superior or both the superior and inferior poles is fused (sigmoid kidney or cake kidney).

As a result of this fusion, the inferior pole of each kidney point medially, ureters leave kidneys and pass anterior to the isthmus, which is typically located immediately below the inferior mesenteric artery. Also, due to the halted ascent, renal vascular anomalies are common: usually, multiple renal arteries arise from the distal aorta or iliac arteries; a wide variety of associated anomalies coexist with HSK, and anomalies for numbers and anatomy are identified in about $80 \%$ of the population [8, 9]. Various classifications for the renal blood supply in HSK were proposed, including the commonly used classification of Eisendrath (Table 5.1).
Table 5.1 Eisendrath's classification of renal blood supply in horseshoe kidney (HSK)

\begin{tabular}{l|l}
\hline Classification & Description \\
\hline Type I & $\begin{array}{l}\text { One renal artery to each side of the } \\
\text { kidney } \\
\text { Type II }\end{array}$ \\
$\begin{array}{l}\text { One renal artery to each side of the } \\
\text { kidney and aortic branches to the } \\
\text { isthmus }\end{array}$ \\
\hline Type III & $\begin{array}{l}\text { Two renal arteries to each side of the } \\
\text { kidney and one to the isthmus }\end{array}$ \\
\hline Type IV & $\begin{array}{l}\text { Two renal arteries to each side of the } \\
\text { kidney, with one or more from iliac } \\
\text { arteries, including isthmus branch }\end{array}$ \\
\hline Type V & $\begin{array}{l}\text { Multiple renal arteries arising from the } \\
\text { aorta, mesenteric, and iliac arteries }\end{array}$ \\
\hline
\end{tabular}

Association between HSK and abdominal aortic aneurysm is extremely rare. The combination was first described by Julian in 1956 [10], and since then, more than 200 cases have been described in scientific literature, of which only one case was a cake kidney, a fusion between both poles. Some reports described AAA wrapped with polyester, when most cases were performed with isthmus separation.

Computed tomography (CT) angiography and three-dimensional CT or magnetic resonance (MR) angiography can identify even small branches or accessory renal arteries that may go unnoticed via other diagnostic imaging techniques.

Planning on a workstation is a critical step of the strategy to establish precise measurements of the different anatomic structures considered. In particular, careful attention has to be paid to the urinary excretal structures.

\subsubsection{Surgical Techniques}

The technical approach to the aorta can be anterior transperitoneal or retroperitoneal, even if the first is the most frequently used [11-14]. However, when arterial disease is limited to the aorta, the retroperitoneal approach avoids problematic dissection of anomalous renal structures [7]. The anterior transabdominal access is preferred in cases of a small isthmus or when the right iliac artery should be reached. This approach assures the best exposure of the kidney, the ureters, the aneurysm, and both iliac vessels; how- 
ever, the renal isthmus can pose a problem in reimplanting aberrant renal arteries. Therefore, in order to obtain adequate aortic exposure, the isthmus can either be divided or excised. Because of the risks of retroperitoneal urinary leaks, infection, bleeding, and renal ischemia, some surgeons consider it prudent to not divide the isthmus [15]. On the other hand, isthmus division does not provoke complications in cases of vessel sacrifice with diameter $<2 \mathrm{~mm}$ or in the presence of fibrotic isthmus. Fortunately, it is often enough to mobilize the isthmus anteriorly to place the aortic graft behind it (Fig. 5.3).

The isthmus section is limited to selective cases, especially complex cases or in emergencies (Fig. 5.4 and Movie 5.2).

The retroperitoneal approach could be particularly advantageous when the isthmus is particularly large or in the presence of a rare renal fusion anomaly of the kidneys, widely known as pancake kidney (also known as discoid kidney, disc kidney, lump kidney, fused pelvic kidney, or cake kidney).

Indeed, this approach, with mobilization of the renal mass and its excretory system toward the right, avoids venous and renal anomalies, and the renal arteries can be identified from the inside of the aneurysmal sac. Nowadays, the management of aneurysmal disease of the aorta in the setting of HSK poses several surgical challenges. Endovascular aortic aneurysm repair (EVAR) has been described in several cases of patients unfit to open repair, showing good early and midterm outcomes [16, 17]. The coverage of accessory renal arteries in patients with HSK represents the main drawback of the endovascular approach. As mentioned before, the anomalous renal arteries $<2 \mathrm{~mm}$ in diameter can be

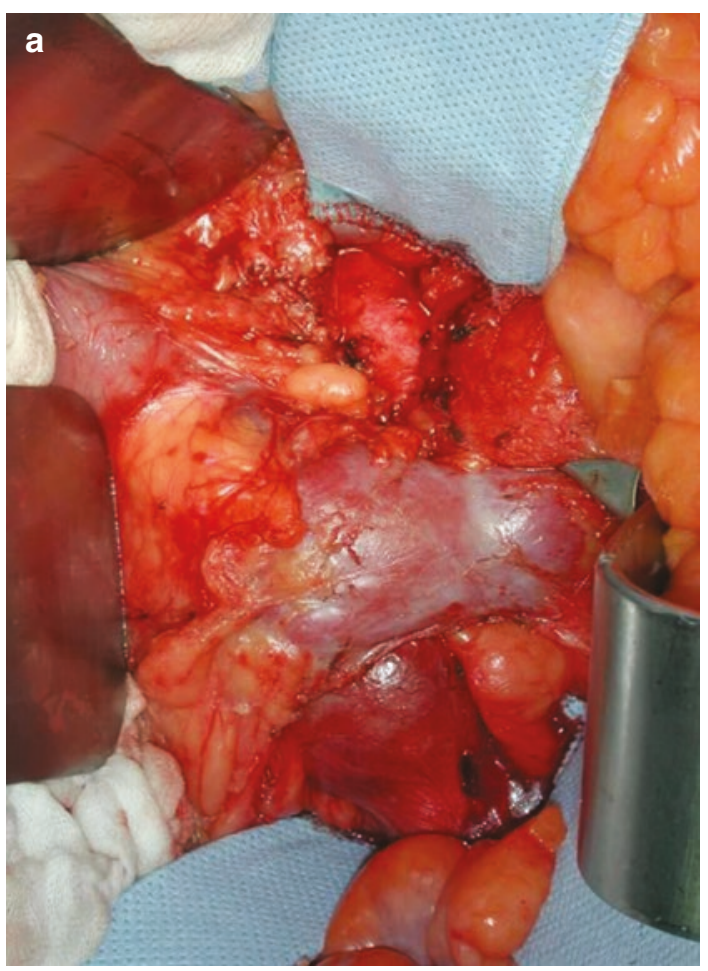

Fig. 5.3 (a) Intraoperative image showing the kidney's isthmus exposed above the abdominal aortic aneurysm (AAA) in a patient with concomitant horseshoe kidney. (b) Identification of the renal arteries from the horseshoe kidney and mobilization of the kidney isthmus. (c) Placing

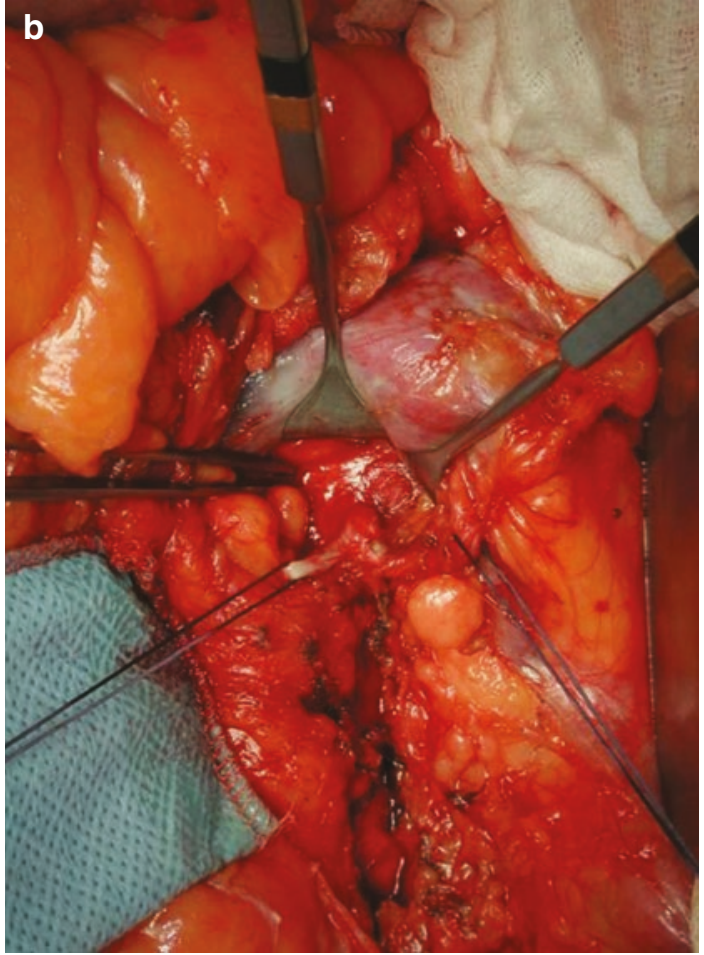

of the aortic graft behind the isthmus of the horseshoe kidney. (d) Final imaging of complete end-to-end aortoaortic Dacron graft bypass reconstruction behind the kidney with renal isthmus and artery preservation 

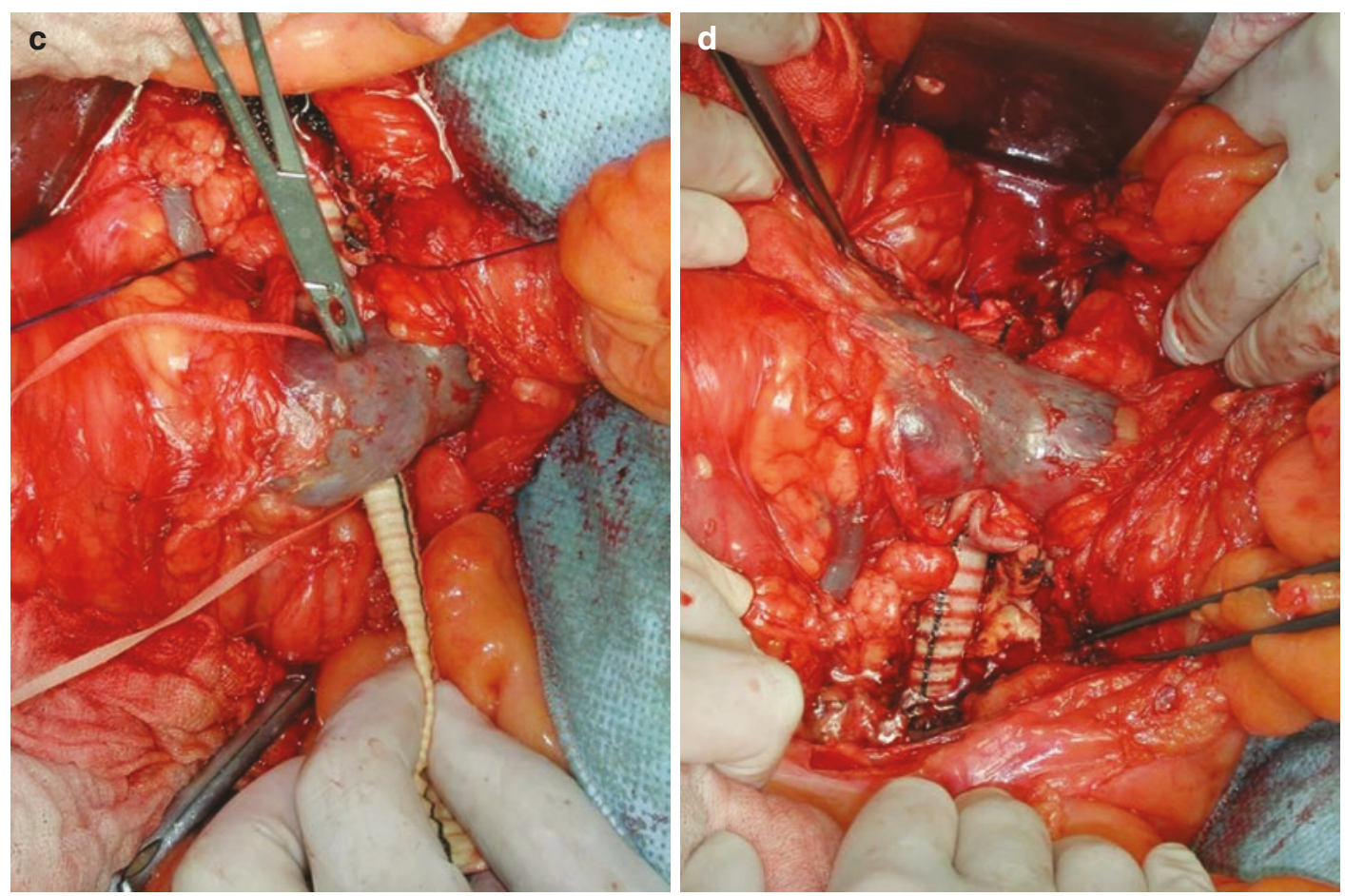

Fig. 5.3 (continued)

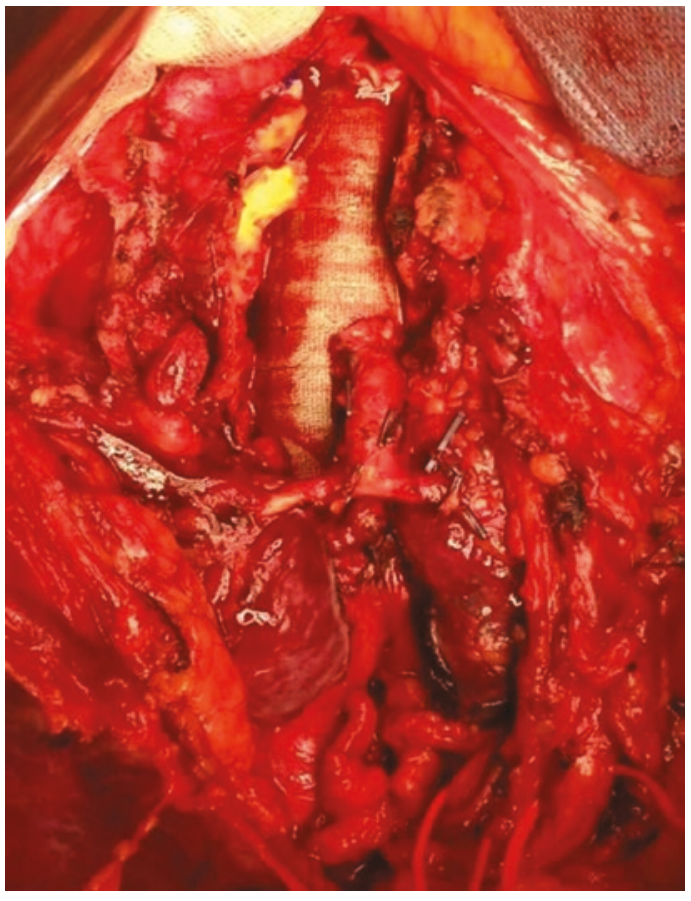

Fig. 5.4 Intraoperative imaging of a ruptured AAA in a patient with concomitant horseshoe kidney. Of note, section and suture of the two stumps at the level of renal isthmus. In Movie 5.1, retroperitoneal hematoma is also shown sacrificed without a real risk of renal ischemia [15]. However, accessory renal arteries of significant size should be preserved in order to prevent renal infarction. Recently, the use of fenestrated or branched endografts could represent a solution to maintain the accessory renal artery perfusion $[18,19]$.

\subsection{Pelvic Kidney}

Ectopic kidney is a less frequent anomaly (0.2$0.03 \%$ ) with variable locations, as shown in Table 5.2 [20, 21].

Embryologic mechanisms leading to ectopic kidneys remain uncertain, and the combination of congenital pelvic kidney with an aortoiliac aneurysm is extremely rare (Figs. 5.5, 5.6, and 5.7).

A radiological study reported that $0.18 \%$ of patients who underwent a major aortic surgery had pelvic kidneys [12]. In 1977, Ezzet et al. [22] documented the first case of a patient with a pelvic kidney associated with AAA. Since then, few cases have been reported in scientific literature. 


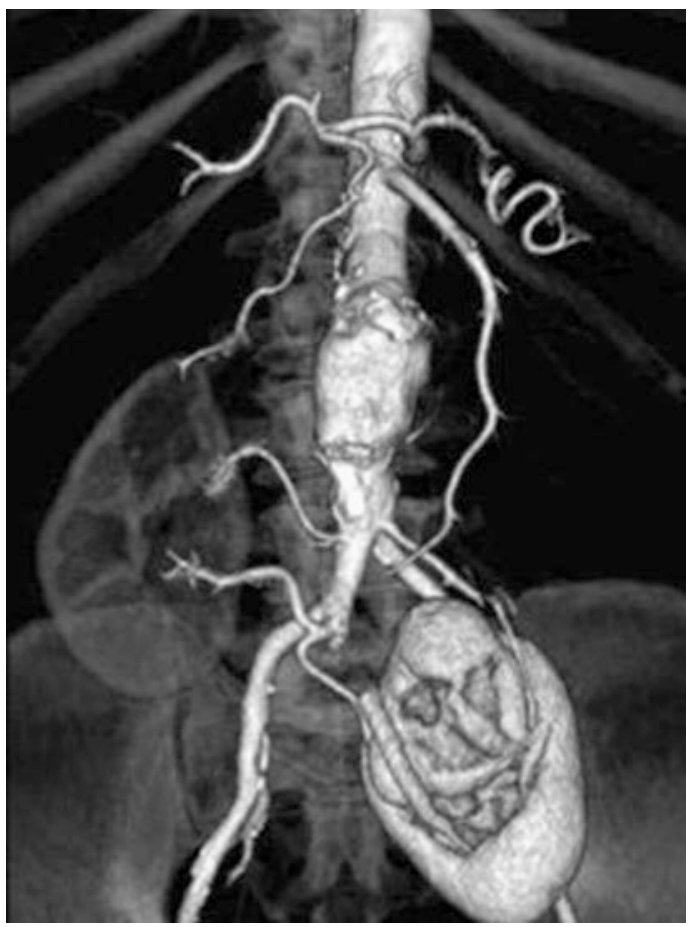

Fig. 5.5 AngioCT showing a case of infrarenal aortic aneurysm associated with ptotic right kidney and left pelvic kidney. Of note, three feeding arteries for the right ptotic kidney originating from the aorta near the superior mesenteric artery, from the origin of the right common iliac artery, and from the right hypogastric artery. Of note, two feeding arteries for the left pelvic kidney originating from the right hypogastric artery and from aortic bifurcation

Table 5.2 Ectopic kidney position

\begin{tabular}{l|l}
\hline Type & Location \\
\hline Pelvic & $\begin{array}{l}\text { Opposite sacrum, distal to the aortic } \\
\text { bifurcation }\end{array}$ \\
\hline Lumbar & $\begin{array}{l}\text { In the iliac fossa, opposite the sacral } \\
\text { promontory }\end{array}$ \\
\hline Abdominal & $\begin{array}{l}\text { Above the iliac crest, adjacent to the L2 } \\
\text { vertebra }\end{array}$ \\
\hline Cephalad & $\begin{array}{l}\text { Below the diaphragm, near the T10 } \\
\text { vertebra }\end{array}$ \\
\hline Thoracic & $\begin{array}{l}\text { Total or partial location in the chest, } \\
\text { above the diaphragm }\end{array}$ \\
\hline Crossed & $\begin{array}{l}\text { Ectopic kidney located on the opposite } \\
\text { side from its ureteral insertion } \\
\text { (1) with fusion, (2) without fusion, (3) } \\
\text { solitary crossed ectopia, and (4) } \\
\text { bilaterally crossed ectopia }\end{array}$ \\
\hline
\end{tabular}

\subsubsection{Surgical Approach and Renal Perfusion}

The surgical approach is usually the anterior transperitoneal approach, which allows for optimal visualization and control of the ectopic renal arteries usually emerging from the iliac arteries and/or distal abdominal aorta (Fig. 5.6).

The technical challenge is in preserving the function of the pelvic kidney. It is also mandatory to preserve renal perfusion to minimize intraoperative renal ischemia.

A variety of techniques have been described to limit ischemic damage to such abnormal pelvic kidneys $[23,24]$. Proximal double clamping of the neck of aneurysm can be used if the aneurysm is entirely limited to the aorta $[25,26]$. This technique was reported for the first time in 1986 by Lacombe et al. [27]. The authors affirmed that it does not render the kidney totally ischemic as the kidney is perfused by retrograde flow in the iliac and the lumbar arteries. When the perfusion of the kidney is completely eliminated, then either perfusion of the kidney with cold solution or surrounding it with ice packs reduces its metabolism, thereby minimizing damage. Using this technique, the kidney needs to be reperfused after about 40-45 min of cold ischemia to avoid any damage. However, this technique is limited if the proximal neck of the aneurysm is not long enough to clamp at two sites or if adequate collateral circulation is not established.

Conventional repair with the administration of furosemide and/or mannitol before cross clamping has also been described. These pharmacological agents are thought to induce diuresis before aortic cross clamping, thereby reducing the risk of acute tubular necrosis.

The main drawbacks of these techniques are that it can be a race against time to perfuse the kidney, and the ischemic insult will result in severe impairment to the kidney whose function is previously compromised.

Other options are cold crystalloid perfusion, passive shunts, and extracorporeal circulation [28, 29].

Cold crystalloid perfusion is a safe and easier method compared to extracorporeal circulation 


\section{a}
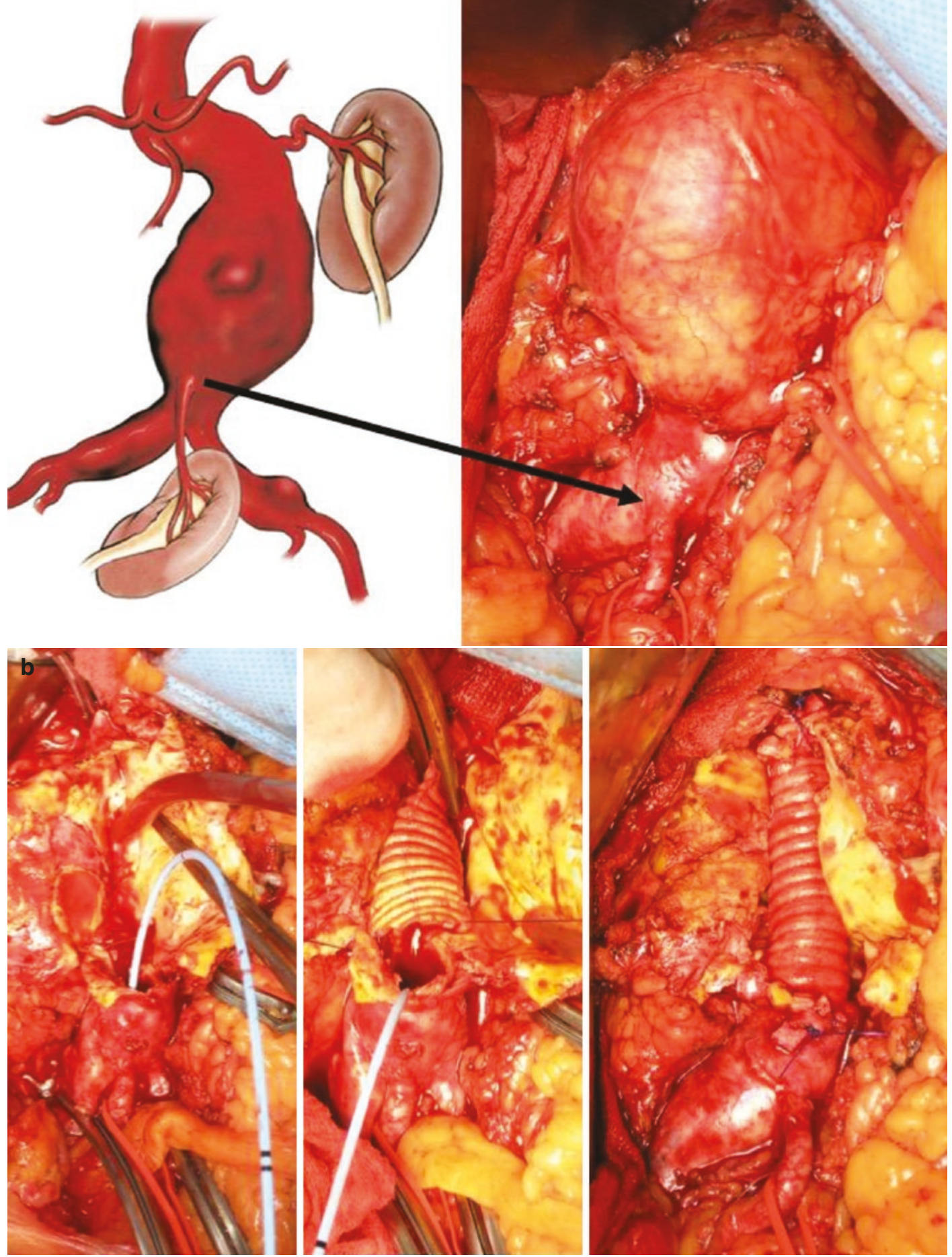

Fig. 5.6 (a) A case of infrarenal aortic aneurysm associated with pelvic kidney with the artery originating from the distal aorta. Schematic illustration (left) and intraoperative image (right) showing the abdominal aortic aneurysm and the pelvic kidney feeding artery (arrow). (b)
Intraoperative images showing perfusion of cold crystalloid into the orifice of the pelvic kidney feeding artery through an occlusion perfusion balloon catheter and endto-end Dacron aortic bypass with the main pelvic kidney renal artery reimplantation 

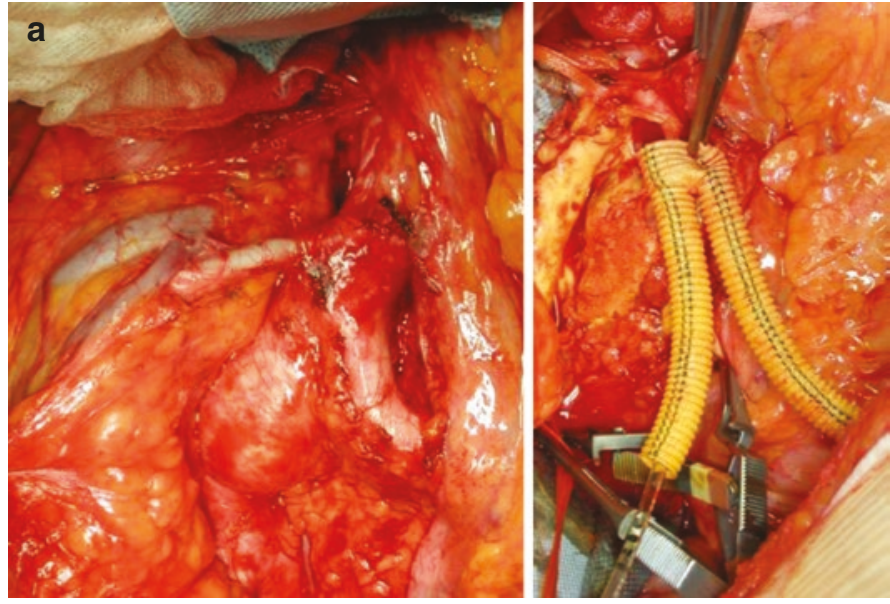

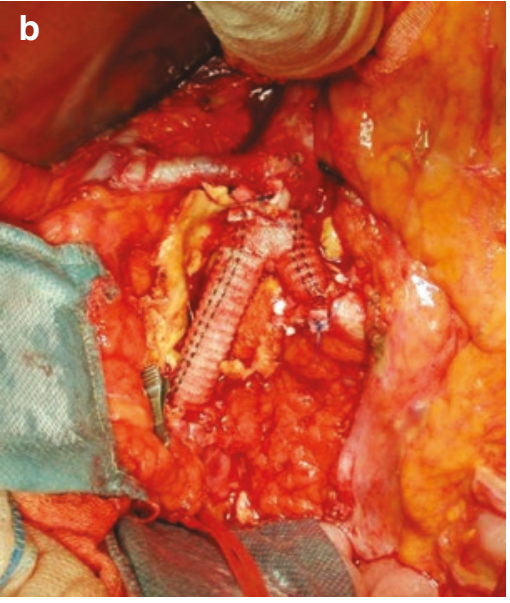

Fig. 5.7 (a) A case of right common iliac aneurysm associated with pelvic kidney with a main artery originating from distal aorta immediately above bifurcation. Of note occlusion perfusion balloon catheter inserted into the right limb of the aorto-bi-iliac Dacron graft in order to perfuse with cold crystalloid solution the orifice of the pelvic kid- ney feeding artery in the distal aorta during proximal anastomosis. (b) Intraoperative images showing Dacron aorto-bi-iliac bypass graft with the pelvic kidney feeding artery immediately above the proximal anastomosis requiring longer renal ischemic time and a pump oxygenator.

As far as the use of a shunt is concerned, embolization and iatrogenic lesions during shunt placement or removal are described [30].

\subsubsection{Endovascular Approach}

In recent years, developments in endovascular repair of pararenal, juxta-renal, and thoracoabdominal aneurysm (TAAA) have been remarkable, representing, in high-risk patients, a valid alternative to open repair.

However, few cases of aortic aneurysm repair with congenital pelvic kidney have been reported to date.

Morales and Greenberg have described the use of a customized fenestrated graft to repair a TAAA in a patient with a left pelvic kidney supplied by a single left pelvic artery arising from around the aortic bifurcation [31]. In 2012, Spear et al. reported their experience in the treatment of renal artery anomalies and aberrant origins of renal arteries, associated or not with pelvic kidney or horseshoe kidney, using fenestrated and branched endografts. The authors showed satisfactory 6-month outcomes and concluded stating that endovascular treatment with fenestrated and branched endografts should be considered in challenging renal artery anomalies in patients unfit for open repair [32].

However, limitations of fenestrated endografts are the target vessel size $<3 \mathrm{~mm}$, and long-term patency rates of these stented arteries may be suboptimal. For these reasons, the use of a customized fenestrated endoluminal graft requires careful preoperative planning and patient selection. This will be an issue to address as fenestrated technology continues to evolve.

\subsection{Venous Abnormalities}

Congenital venous abnormalities in the retroperitoneal space are relatively infrequent and, under normal circumstances, asymptomatic but have clinical importance in aortoiliac surgery. These anomalies have a low prevalence $(5.65 \%)$ [33, 34]: type I retroaortic left renal vein (LRV), with an incidence of $0.3-0.9 \%$ joining the inferior vena cava (IVC) in orthotopic position [34] (Fig. 5.8); type II LRV that joins the IVC lower, at L4-L5 (0.4-0.9\%) [35]; circumaortic renal 

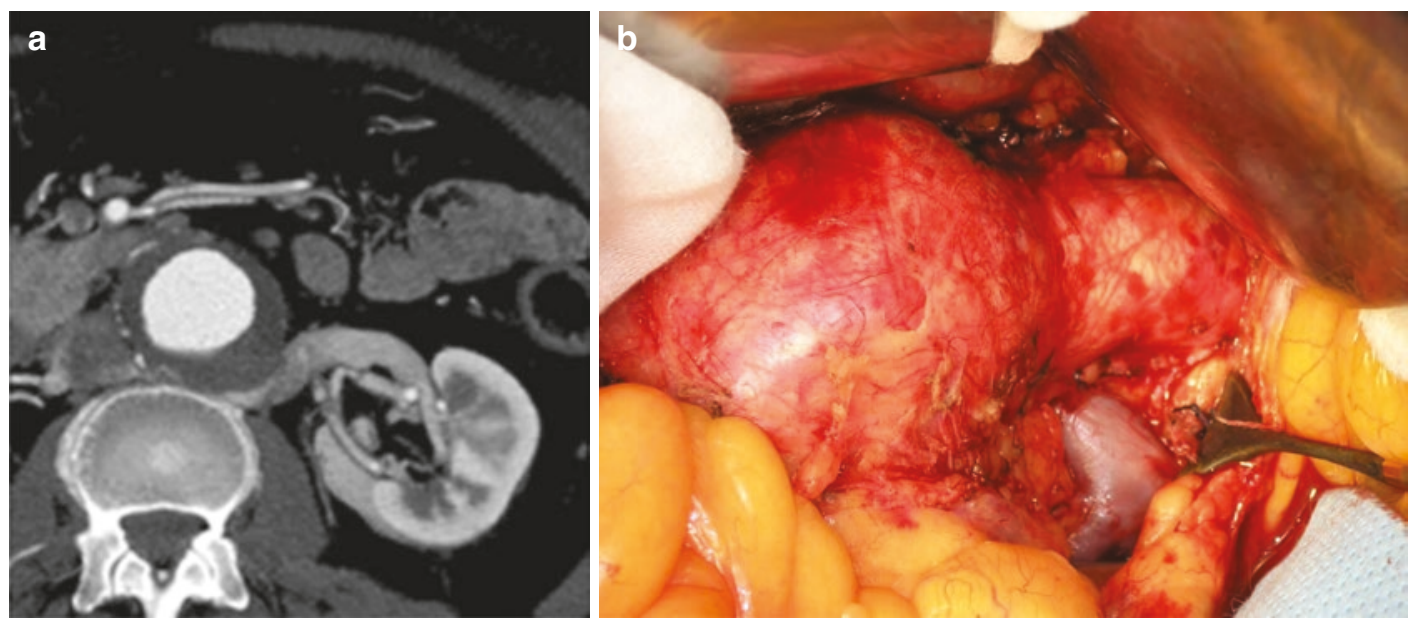

Fig. 5.8 (a) AngioCT showing a retroaortic left renal vein in a patient with infrarenal abdominal aortic aneurysm. (b) Intraoperative images showing a retroaortic left renal vein in a patient with infrarenal abdominal aortic aneurysm

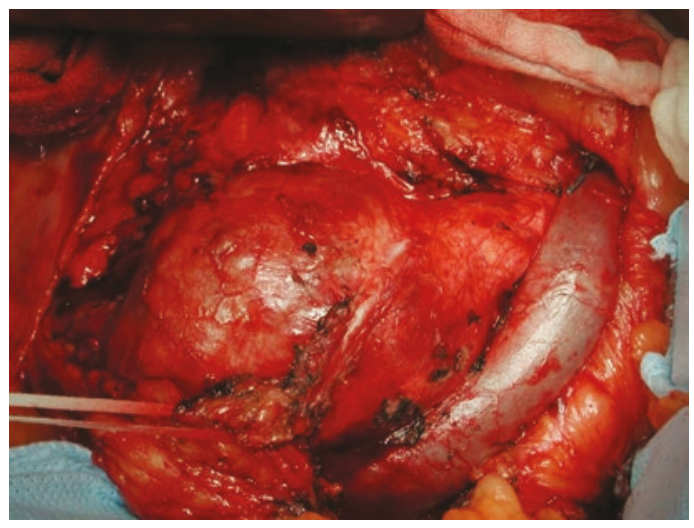

Fig. 5.9 Intraoperative images showing a left-sided inferior vena cava in a patient with infrarenal abdominal aortic aneurysm

collar (0.5-1.4\%) [36]; left-sided IVC (Figs. 5.9 and 5.10) and duplication of IVC (0.2-3\%) [37] (Fig. 5.10); and the least common anomaly (0.2$0.5 \%)[33,35]$. The presence of vascular anatomical anomalies can create technical difficulties during aortoiliac surgery, and the patients are most likely to suffer severe bleeding; thus, the surgeon must be alert to detect these anomalies.

There are some variants:

- Retroaortic LRV type I. The ventral preaortic limb of the renal venous collar is obliterated, and the dorsal limb remains on the contrary of the normal evolution, joining the IVC in an orthotopic position, in the neck of the aneurysm.

- Retroaortic LRV type II. The dorsal limb is detected in a lower position, at L4-L5, behind the aneurysm, and joins the IVC, gonadal, or ascending lumbar veins.

- In the circumaortic LRV, both preaortic and retroaortic limbs of the venous collar persist patent.

- Transposition or left-sided IVC develops from the persistence of the left instead of right supracardinal vein, which occurs in the normal evolution. The left-sided infrarenal IVC typically joins the LRV, before it crosses the aorta to form a normal right-sided suprarenal IVC. A complete transposition of the IVC to the left with hemizygous continuation is extremely rare. This case can present itself with or without situs viscerum inversus.

- In the duplication of the IVC, both left and right supracardinal veins persist.

- Preaortic confluence of the iliac veins.

- Although no other anomaly has been encountered behind the left renal vein during this period, communication between the left ascending lumbar vein and the left renal vein is sometimes experienced [38]. 

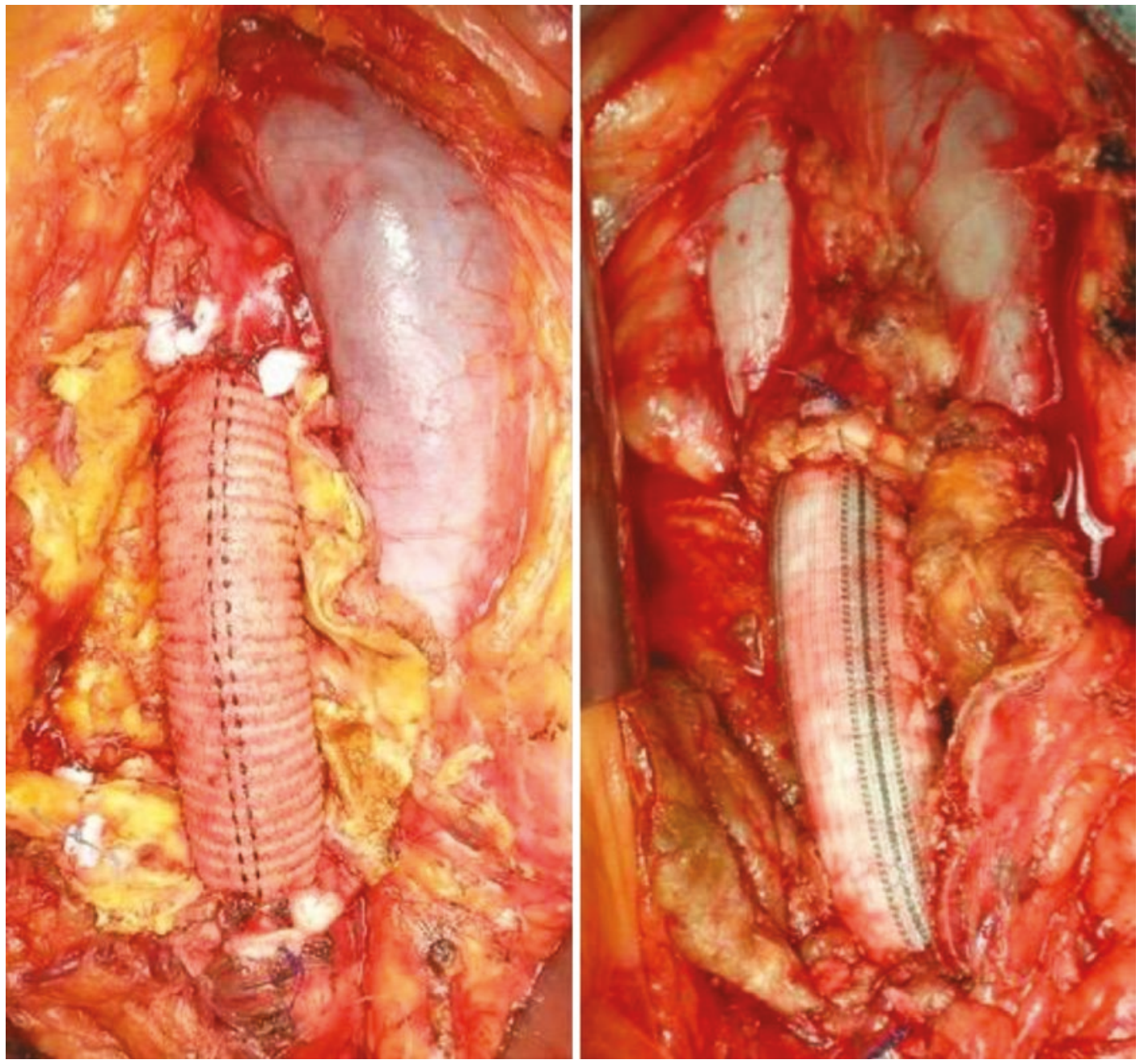

Fig. 5.10 Intraoperative images showing infrarenal aortic tube graft repair in a patient with a left-sided inferior vena cava (left) and a duplication of inferior vena cava (right)

- The superior lumbar veins can be also terminated to the dorsal aspect of the left renal vein [39].

Venous hemorrhage is the most troublesome complication during AAA surgery, occurring particularly during dissection of the proximal infrarenal and lower aorta, the level of CIAs [40].

During elective surgery for AAA, the presence of these rare anomalies can be managed with little additional risk through the use of a long midline incision and transperitoneal route. With a careful blunt dissection, it is possible to gain proximal and distal control mobilizing the "unconventional" caval conformation, which may result strictly adherent to the aorta.

These considerations are valid even in the presence of Kartagener's syndrome.

On the other hand, a large series of aortic interventions showed that the LRV can be readily divided adjacent to the inferior vena cava in order to provide improved exposure during complex aortic reconstruction. Theoretical disadvantages of renal vein ligation such as flank pain or hematuria were not noted in this series [41]. 


\subsection{Conclusion}

An in-depth knowledge of variations in the anatomy of the kidneys is mandatory before planning an aortoiliac aneurysm repair. Both arterial and venous vascular anatomies should be carefully evaluated together with possible more complex changes including congenital fusion disorders and ectopia. Accurate preoperative planning with advanced image studies including CT scan or MRN angiography, and, in selected cases, renal artery arteriography and DUS, for complete knowledge of renal vascular anatomy is the key of success in more complex cases. To preserve renal function during open repair, various methods have been reported, but no procedure has still been clearly assessed as the therapeutic gold standard. However, strategies based on reduced renal clamping time, renal branch reattachment/preservation, and renal perfusion with blood or cold crystalloid seem to be effective in minimizing ischemia-reperfusion renal damage.

In selected cases, endovascular repair with fenestrated/branched endografts or CHIMPS may represent an alternative to open repair, even if larger series and longer follow-up are needed.

\section{References}

1. Glenn J. Analysis of 51 patients with horseshoe kidney. N Engl J Med. 1959;261:684-7.

2. Sidell PM, Pairolero PC, Payne WS, Bernatz PE, Spittel JA Jr. Horseshoe kidney associated with surgery of the abdominal aorta. Mayo Clin Proc. 1979;54:97-103.

3. Bauer SB, Perlmutter AD, Retik AB. Anomalies of the upper urinary tract. In: Walsh PC, editor. Campbell's urology. 6th ed. Philadelphia: WB Saunders; 1992. p. 1357-44.

4. O'Hara PJ, Hakaim AG, Hertzer NR, Herzer NR, Krajewski LP, Cox GS, et al. Surgical management of aortic aneurysm and coexistent horseshoe kidney: review of a 31 year experience. J Vasc Surg. 1993;17:940-7.

5. Glodny B, Petersen J, Hofmann KJ, Schenk C, Herwig R, Treb T, et al. Kidney fusion anomalies revisited: clinical and radiological analysis of 209 cases of crossed fused ectopia and horseshoe kidney. BJU Int. 2009; 103:224-35.
6. Grainger R, Murphy DM, Lane V. Horseshoe kidneya review of the presentation, associated congenital anomalies and complications in 73 patients. Ir Med J. 1983;76:315-7.

7. Faggioli GL, Freyrie A, Pilato A, Ferri M, Curti T, Paragona O, D'Addato M. Renal anomalies in aortic surgery: contemporary results. Surgery. 2003;133:641-6.

8. Boujnh H, Abid I, Moalla N, Zmerli S. Le rein pelvien. Ann Urol. 1989;23:11-6.

9. Eisendrath DN, Phifer FM, Culver HB. Horseshoe kidney. Ann Surg. 1926;82:735-64.

10. Phelan JT, Bernatz PE, DeWeerd JH. Abdominal aortic aneurysm associated with a horseshoe kidney: report of a case. Mayo Clin Proc. 1957;32:77-81.

11. Bietz DS, Merendno KA. Abdominal aneurysm and horse- shoe kidney: a review. Ann Surg. 1975;181:333-41.

12. Brewster DC, Retana A, Waltman AC, Darling RC. Angiography in the management of aneurysms of the abdominal aorta: its value and safety. N Engl J Med. 1975;292:822-5.

13. Connelly TL, McKinnon W, Smith RB III, Perdue GD. Abdominal aortic surgery and horseshoe kidney: report of six cases and a review. Arch Surg. 1980;115:1459-63.

14. Shortell CK, Welch EL, Ouriel K, et al. Operative management of coexistent aortic disease and horseshoe kidney. Ann Vasc Surg. 1995;9:123-8.

15. Canova G, Masini R, Santoro E, et al. Surgical treatment of abdominal aortic aneurysm in association with horseshoe kidney. Three case reports and a review of technique. Tex Heart Inst J. 1998;25:206-10.

16. Ilic NS, Koncar I, Dragas M, Cvetkovic S, Pejkic S, Kostic D, et al. Technical considerations for transabdominal aortic reconstruction with renal fusion and ectopia: case series. Vascular. 2010;18(5):269-74.

17. Martin MC, Giles KA, Pomposelli FB, Hamdan AD, Wyers MC, Schermerhorn ML. National outcomes after open repair of abdominal aortic aneurysms with visceral or renal bypass. Ann Vasc Surg. 2010;24(1):106-12.

18. Greenberg RK, Lu Q, Roselli EE, et al. Contemporary analysis of descending thoracic and thoracoabdominal aneurysm repair: a comparison of endovascular and open techniques. Circulation. 2008;118:808-17.

19. Chuter TA, Rapp JH, Hiramoto JS, Schneider DB, Howell B, Reilly LM. Endovascular treatment of thoracoabdominal aortic aneurysms. J Vasc Surg. 2008;47:6-16.

20. Faggioli GL, Tarantini S, Stella A, D'Addato M. Aneurisma dell' aorta addominale associato a rene ectopico pelvico e stenosi dell' arteria renale. G It Chir Vasc. 1994;1:47-54.

21. Thompson GJ, Pace JM. Ectopic kidney: a review of 97 cases. Surg Gynecol Obstet. 1937;64:935.

22. Ezzet F, Dorazio R, Herzberg R. Horseshoe and pelvic kidneys associated with abdominal aortic aneurysms. Am J Surg. 1977;134:196-8. 
23. O’Hara PJ, Hakaim AG, Hertzer NR, Krajewski LP, Cox GS, Beven EG. Surgical management of aortic aneurysm and coexistent horseshoe kidney: review of 31-year experience. J Vasc Surg. 1993;17:940-7.

24. Eckes D, Lawrence P. Bilateral iliac artery aneurysms and pancake kidney: a case report. J Vasc Surg. 1997;25:927-30.

25. Hollis HW Jr, Rutherford R, Crawford GJ, Cleland BP, Marx WH, Clark JR. Abdominal aortic aneurysm repair in patients with pelvic kidney-technical considerations and literature review. J Vasc Surg. 1989;9:404-9.

26. Schneider JR, Cronenwett JL. Temporary perfusion of congenital pelvic kidney during abdominal aortic aneurysm repair. J Vasc Surg. 1993;17:613-7.

27. Lacombe M. Abdominal aortic aneurysmectomy in renal transplant patients. Ann Surg. 1986;203:62-8.

28. Marone EM, Tshomba Y, Brioschi C, Calliari FM, Chiesa R. Aorto-iliac aneurysm associated with congenital pelvic kidney: a short series of successful open repairs under hypothermic selective renal perfusion. J Vasc Surg. 2008;47:638-44.

29. Campbell DA Jr, Lorber MI, Arneson WA, Kirsh MM, Turcotte JG, Stanley JC. Renal transplant protection during abdominal aortic aneurysmectomy with a pump-oxygenator. Surgery. 1981;90:559-62.

30. Sterioff S, Parks L. Temporary vascular bypass for perfusion of a renal transplant during abdominal aneurysmectomy. Surgery. 1977;82:558-60.

31. Morales JP, Greenberg RK. Customised stent graft for complex thoraco-abdominal aneurysm associated with congenital pelvic kidney. Eur J Vasc Endovasc Surg. 2009;37:557-9.

32. Spear R, Maurel B, Sobocinski J, Perini P, Guillou M, Midulla M, Azzaoui R, Tefera G, Haulon S. Technical note and results in the management of anatomical variants of renal vascularisation during endovas- cular aneurysm repair. Eur J Vasc Endovasc Surg. 2012;43(4):398-403.

33. Aljabri B, McDonald PS, Satin R, Stein LS, Obrand DI, Steinmetz OK. Incidence of major venous and renal anomalies relevant to aortoiliac surgery as demonstrated by computed tomography. Ann Vasc Surg. 2001;15:615-8.

34. Minniti S, Procacci C. Congenital anomalies of the vena cava: embryological origin, imaging features and report of three new variants. Eur Radiol. 2002;12:2040-55.

35. Bass JE, Redwine MD, Kramer LA, Huynh PT, Harris JH. Spectrum of congenital anomalies of the inferior vena cava: cross-sectional imaging findings. Radiographics. 2000;20:639-52.

36. Giglia JS, Thompson JK. Repair of a thoracoabdominal aortic aneurysm in the presence of a left-sided inferior vena cava. J Vasc Surg. 2004;40:161-3.

37. Karkos CD, Bruce IA, Thomson GJL, Lambert ME. Retroaortic left renal vein and its implications in abdominal aortic surgery. Ann Vasc Surg. 2001;15:703-8.

38. Pilcher JM, Padhani AR. Problem in diagnostic imaging: behind the left renal vein. Clin Anat. 1997; 10:349-52.

39. Davis RA, Milloy FJ, Anson BJ. Lumbar, renal, and associated parietal and visceral veins based upon a study of 100 specimens. Surg Gynecol Obstet. 1958;107:1-22.

40. Brener BJ, Darling RC, Frederich PL, Linton RR. Major venous anomalies complicating abdominal aortic surgery. Arch Surg. 1974;108:159-65.

41. Russell H, Samson MD, Michael R, Lepore MD Jr, David P, Showalter MD, Deepak G, Nair MD, Julien B, Lanoue S. Long-term safety of left renal vein division and ligation to expedite complex abdominal aortic surgery. J Vasc Surg. 2009;50:500-4. 